\title{
HUBUNGAN KEJADIAN ACNE VULGARIS DENGAN KEPERCAYAAN DIRI PADA SISWI KELAS XI DI SMAN 2 BANGKINANG KOTA
}

\author{
Rinda Fithriyana \\ Program Studi DIII Kebidanan Universitas Pahlawan Tuanku Tambusai \\ rindaup@gmail.com
}

\begin{abstract}
Abstrak
Acne vulgaris merupakan penyakit kulit yang umum terjadi sekitar 85 hingga 100 persen selama hidup seseorang. Acne vulgaris sering dijumpai pada wanita yang berusia 14 hingga 17 tahun dan 16-19 tahun pada laki-laki. Di Indonesia angka kejadian acne vulgaris berkisar 85\% dan terjadi pada usia 14-17 tahun pada wanita dan 16-19 tahun pada laki-laki, dengan lesi perdominan adalah komedo dan papul. Tujuan penelitian ini adalah untuk mengetahui hubungan acne vulgaris dengan kepercayaan diri pada siswi kelas XI DI SMAN 2 Bangkinang Kota tahun 2018. Jenis penelitian ini adalah analitik dengan rancangan cross sectional. Populasi dalam penelitian ini adalah seluruh siswi kelas XI yang mengalami acne vulgaris di SMAN 2 Bangkinang Kota yang berjumlah 73 orang, teknik pengambilan sampel menggunakan total sampling. Alat pengumpulan data dalam penelitian ini adalah menggunakan kuesioner. Analisa data dalam penelitian ini menggunakan analisa univariat dan bivariat. Hasil penelitian diperoleh bahwa sebagian besar responden mengalami acne vulgaris dengan jenis papula yaitu sebanyak 39 orang $(53,4 \%)$, sebagian besar responden memiliki kepercayaan diri yang negatif yaitu sebanyak 40 orang $(54,8 \%)$ dan terdapat hubungan yang sugnifikan antara acne vulgaris dengan kepercayaan diri pada siswi di SMAN 2 Bangkinang Kota tahun 2017 dengan p value $0,002(\mathrm{p}<0,05)$. Diharapkan pada remaja putri yang menderita acne vulgaris agar dapat selalu percaya diri jika terjadi acne vulgaris.
\end{abstract}

Kata Kunci: acne vulgaris, kepercayaan diri, remaja

\begin{abstract}
Acne vulgaris is a common skin disease that occurs around 85 to 100 percent during a person's life. Acne vulgaris is often found in women aged 14 to 17 years and 16-19 years in men. In Indonesia the incidence of acne vulgaris ranges from $85 \%$ and occurs at the age of 14-17 years in women and 16-19 years in men, with the dominant lesions are blackheads and papules. The purpose of this study was to determine the relationship of acne vulgaris with confidence in class XI students at SMAN 2 Bangkinang Kota in 2018. This type of research is analytic with cross sectional design. The population in this study were all class XI students who experienced acne vulgaris in SMAN 2 Bangkinang Kota, amounting to 73 people, the sampling technique used total sampling. Data collection tool in this study is to use a questionnaire. Analysis of the data in this study using univariate and bivariate analysis. The results showed that the majority of respondents experienced acne vulgaris with papules as many as 39 people (53.4\%), the majority of respondents had negative self-confidence as many as 40 people (54.8\%) and there was a significant relationship between acne vulgaris with confidence in students in SMAN 2 Bangkinang Kota in 2017 with $p$ value 0.002 ( $p<0.05$ ). It is expected that young women who suffer from acne vulgaris can always be confident in case of acne vulgaris.
\end{abstract}

Keywords: acne vulgaris, self confidence, teenagers

@ Jurnal Ners Prodi Sarjana Keperawatan \& Profesi Ners FIK UP 2019

$\triangle$ Corresponding author :

Address : Jl. Tuanku Tambusai No. 23 Bangkinang

Email : rindaup@gmail.com

Phone : 08127589128 


\section{PENDAHULUAN}

Semua orang tentu mendambakan kulit sehat dan cantik. Hanya saja posisinya sebagai bagian paling luar dari tubuh manusia membuat kulit sangat rentan mengalami berbagai masalah dan gangguan kesehatan. Hal ini karena kulit tidak dapat terhindar dari bersentuhan dengan debu, kotoran, polusi udara, berbagai zat kimia yang terkandung dalam kosmetik, air yang tidak bersih dan sebagainya. Semua ini berpotensi menimbulkan gangguan pada kulit salah satunya adalah jerawat (Achroni 2012 dalam Ellin dkk, 2015)

Acne vulgaris adalah salah satu penyakit kulit yang selalu menjadi masalah bagi remaja dan dewasa muda. Prevalensi yang mencapai $90 \%$ menjadikan acne penyakit yang ditakuti oleh remaja bahkan dewasa muda. Onset terjadinya acne vulgaris dimulai saat masa pubertas yaitu pada rentang usia 14-19 tahun pada pria dan 10-17 tahun pada wanita (Johnson, 2015).

Acne vulgaris memiliki patogenesis yang belum jelas secara umum pathogenesis acne melibatkan proses peningkatan ekskresi dari sebum, hiperkeratosis dari duktus pilosebaceus, kolonisasi Propionibacterium acnes di duktus serta pelepasan mediator inflamasi dan respon imun (Gawkrodger, 2009).

Bakteri penyebab jerawat ini adalah Propionibacterium acnes. Bakteri ini merusak siratum curneum dan siratum germinativum dengan cara mensekresikan bahan kimia yang menghancurkan dinding pori. Kondisi ini dapat menyebabkan inflamasi. Asam lemak dan minyak kulit tersumbat dan mengeras. Jika jerawat disentuh maka inflamasi akan meluas sehingga padatan asam lemak dan minyak kulit yang mengeras akan membesar sehingga terbentuklah jerawat. (Hartini dkk, 2012).

Di Amerika acne vulgaris adalah penyakit kulit yang umum dan ditandai oleh peradangan, baik terbuka maupun tertutup yaitu peradangan komedo, papula, pustula dan nodul. Ini terjadi sekitar 60 hingga persen selama hidup mereka. $20 \%$ akan memiliki jerawat yang parah sehingga dapat berakibat pada fisik dan mental dan menimbulkan jaringan parut permanen (Hartini dkk, 2012).

Di Indonesia angka kejadian acne vulgaris berkisar $85 \%$ dan terjadi pada usia 14-17 tahun pada wanita dan 16-19 tahun pada laki-laki, dengan lesi perdominan adalah komedo dan papul. Acne vulgaris umumnya lebih banyak terjadi pada laki-laki dibandingkan dengan wanita pada rentang usia 15-44 tahun yaitu 34\% pada laki-laki dan 27\% pada wanita. Acne vulgaris merupakan penyakit kulit yang umum terjadi sekitar 85 hingga 100 persen selama hidup seseorang. Acne vulgaris sering dijumpai pada wanita yang berusia 14 hingga 17 tahun dan pada pria berusia 16 hingga 19 tahun (Kurniawaty, 2010).

Dengan munculnya jerawat pada masa remaja, maka kesadaran akan pentingnya penampilan diri dalam kehidupan sosial yang pada akhirnya dapat mempengaruhi konsep diri remaja. Konsep diri adalah semua perasaan, kepercayaan, dan nilai yang diketahui individu tentang dirinya dan mempengaruhi individu dalam berhubungan dengan orang lain. Konsep diri terdiri dari lima komponen yaitu: Citra diri (body image), ideal diri, penampilan peran, identitas personal dan kepercayaan diri (Hasan, 2014).

Kepercayaan diri merupakan suatu keyakinan dalam jiwa manusia bahwa tantangan hidup apapun harus di hadapi dengan berbuat sesuatu. Kepercayaan diri itu lahir dari kesadaran bahwa jika memutuskan untuk melakukan sesuatu, sesuatu itu pula yang harus dilakukan. Kepercayaan diri itu akan datang dari kesadaran seorang individu bahwa individu tersebut memiliki tekat untuk melakukan apapun, sampai tujuan yang ia inginkan tercapai (Yunita, 2013).

Acne vulgaris juga memiliki dampak terhadap kualitas hidup manusia. Selain mempunyai efek negative pada kulit, acne vulgaris juga memiliki efek negative pada psikologis antara lain dapat mengalami depresi sehingga menurunkan kualitas hidupnya, rasa malu serta berkurangnya kepercayaan diri (Gawkrodger, 2009).

Hasil penelitian yang dilakukan oleh Farmiyati (2009), diketahui bahwa konsep diri dari 62 siswi berjerawat di SMA Muhammadiyah 1 Semarang sebagian besar adalah dalam kategori buruk yaitu $40,3 \%$. Konsep diri yang sebagian besar buruk ini disebabkan karena para remaja putri kurang menyadari tentang harga diri dan kepercayaan dirinya sendiri. Remaja putri tampak kurang menyukai perubahan fisik mengenai acne vulgaris. Acne vulgaris ini dapat menyebabkan remaja putri seringkali merasa malu dan menutup diri terhadap 
lingkungan. sulitnya untuk membangun suatu hubungan personal, bertemu orang yang baru dikenal maupun berhadapan dengan lawan jenis. Berbeda dengan remaja putra yang cenderung menerima apa adanya yang mereka alami seiring pubertas. Dengan munculnya acne vulgaris pada masa remaja, maka kesadaran akan pentingnya penampilan diri dalam kehidupan sosial yang pada akhirnya dapat mempengaruhi kepercayaan diri remaja putri (Al-Hoqail, 2008).

Berdasarkan data yang diperoleh dari 3 sekolah yang ada di Kabupaten Kampar yaitu SMAN 1 Bangkinang Kota, SMAN 2 Bangkinang Kota dan SMAN 1 Kuok, diperoleh bahwa SMAN 2 Bangkinang Kota merupakan sekolah yang memiliki jumlah murid terbanyak yaitu 1032 siswa dan kelas XI merupakan data siswa terbanyak yaitu berjumlah 363 orang.

Berdasarkan survey awal yang dilakukan pada kelas XI di SMAN 2 Bangkinang terhadap 10 orang siswa, didapatkan bahwa 6 orang siswa terkena acne vulgaris, dan mereka mengatakan bahwa ada yang berubah terutama pada dirinya karena ketidaknyamanan disekitar wajah dan tidak sama seperti teman sebayanya yang tidak mempunyai jerawat, mereka merasa kurang percaya diri, malu, kurang kontak mata saat diajak bicara, berusaha selalu memalingkan muka serta kurang semangat dalam melakukan aktifitas.

Berdasarkan latar belakang peneliti tertarik untuk melakukan penelitian dengan judul hubungan acne vulgaris dengan kepercayaan diri pada siswi kelas XI di SMAN 2 Bangkinang Kota Tahun 2018.

\section{METODE}

\section{Desain Penelitian}

Jenis penelitian ini adalah analitik dengan rancangan cross sectional (potong lintang), yaitu setiap variabel diobservasi hanya satu kali saja dan pengukuran masing-masing variabel dilakukan pada waktu yang sama (Notoatmodjo, 2010). Penelitian ini menggunakan jenis penelitian korelasional karena bertujuan untuk menjelaskan hubungan antara kejadian acne vulgaris dengan kepercayaan diri pada siswi kelas XI di SMAN 2 Bangkinang Kota.

\section{Lokasi dan Waktu Penelitian}

Penelitian ini dilaksanakan di SMAN 2 Bangkinang Kota pada tanggal 20-24 Juli 2018.

\section{Populasi}

Populasi adalah keseluruhan subjek penelitian (Notoatmodjo, 2010). Populasi pada penelitian ini adalah seluruh siswi kelas XI yang mengalami acne vulgaris di SMAN 2 Bangkinang Kota yang berjumlah 73 orang.

\section{Sampel}

Sampel adalah sebagian objek yang diambil dari keseluruhan objek yang diteliti yang dianggap mewakili seluruh populasi (Hidayat, 2014). Yang menjadi sampel dalam penelitian ini adalah sebagian siswa kelas XI yang mengalami acne vulgaris di SMAN 2 Bangkinang Kota. Teknik pengambilan sampel yang digunakan dalam penelitian ini adalah total samping, yaitu pengambilan sampel yang diambil dari keseluruhan populasi. Besar sampel dalam penelitian ini adalah sebanyak 73 siswi yang mengalami acne vulgaris.

\section{Alat Pengumpulan Data}

Alat pengumpulan data yang digunakan dalam penelitian ini adalah kuesioner. Untuk kuesioner kepercayaan diri berjumlah 15 pertanyaan menggunakan skala likert yang terdiri dari 4 jawaban alternatif. Masing-masing diberi nilai yaitu untuk pertanyaan positif : sangat setuju $=4$, setuju $=3$, tidak setuju $=2$, sangat tidak setuju $=1$ dan untuk pertanyaan negatif: sangat setuju $=1$, setuju $=2$, tidak setuju $=3$, sangat tidak setuju $=$ 4. Untuk kuesioner acne vulgaris terdiri dari 1 pernyataan, dimana pernyataan tersebut dilakukan dengan observasi langsung kepada responden dengan acne vulgaris.

Analisa Data
Analisa yang digunakan adalah analisa
univariat dan analisa bivariat. Analisis univariat
adalah analisa yang dilakukan terhadap tiap
variabel dari hasil penelitian, analisis ini
menghasilkan distribusi dan persentase dari tiap
variabel (Notoatmodjo, 2010). Analisis ini
bermanfaat untuk memberi gambaran karakteristik
subyek penelitian dengan menghitung distribusi
frekuensi dan proporsi. Analisa bivariat digunakan
untuk meliihat hubungan antara variabel


independen dengan variabel dependen. Analisa bivariat akan menggunakan uji Chi-Square $\left(\mathrm{X}^{2}\right)$ dengan menggunakan tingkat kepercayaan $95 \%$.

\section{HASIL DAN PEMBAHASAN}

Penelitian ini bertujuan untuk mengetahui hubungan kejadian acne vulgaris dengan kepercayaan diri pada siswi di SMAN 2 Bangkinang Kota tahun 2017. Penelitian ini dilakukan pada tanggal 20-24 Juli 2017 dengan jumlah sampel sebanyak 73 responden. Dari hasil pengumpulan data disajikan sebagai berikut:

\section{Analisis Univariat}

Tabel 1: Distribusi Frekuensi Resonden Berdasarkan Acne Vulgaris di SMAN 2 Bangkinang Kota Tahun 2018

\begin{tabular}{clcc}
\hline No & $\begin{array}{c}\text { Jenis Acne } \\
\text { Vulgaris }\end{array}$ & Frekuensi & Persentase (\%) \\
\hline 1 & Komedo & 31 & 42,5 \\
2 & Papula & $\mathbf{3 9}$ & $\mathbf{5 3 , 4}$ \\
3 & Pustule & 3 & 4,1 \\
\hline & Jumlah & $\mathbf{7 3}$ & $\mathbf{1 0 0}$ \\
\hline
\end{tabular}

Berdasarkan tabel 1 dapat dilihat bahwa sebagian besar responden menderita acne vulgaris dengan jenis papula yaitu sebanyak 39 orang $(53,4 \%)$.

Tabel 2: Distribusi Frekuensi Responden berdasarkan kepercayaan diri di SMAN 2 Bangkinang Kota Tahun 2018

\begin{tabular}{cccc}
\hline No & Kepercayaan diri & Frekuensi & Persentase (\%) \\
\hline $\mathbf{1}$ & Negatif & $\mathbf{4 0}$ & $\mathbf{5 4 , 8}$ \\
2 & Positif & 33 & 45,2 \\
\hline \multicolumn{2}{c}{ Jumlah } & $\mathbf{7 3}$ & $\mathbf{1 0 0}$ \\
\hline
\end{tabular}

Berdasarkan tabel 2 dapat di lihat bahwa sebagian besar responden memiliki kepercayaan diri yang negatif yaitu sebanyak 40 orang $(54,8 \%)$.

\section{Analisa Bivariat}

Tabel 3: Hubungan Acne Vulgaris dengan kepercayaan diri di Bangkinang tahun 2017

\begin{tabular}{|c|c|c|c|c|c|c|c|}
\hline \multirow{3}{*}{$\begin{array}{l}\text { Acne } \\
\text { vukgaris }\end{array}$} & \multicolumn{4}{|c|}{ Kepercayaan diri } & \multirow{2}{*}{\multicolumn{2}{|c|}{ Total }} & \multirow{3}{*}{$\begin{array}{c}\mathrm{P} \\
\text { value }\end{array}$} \\
\hline & \multicolumn{2}{|c|}{ Negatif } & \multicolumn{2}{|c|}{ Positif } & & & \\
\hline & $\mathrm{n}$ & $\%$ & $\mathrm{n}$ & $\%$ & $\mathrm{~N}$ & $\%$ & \\
\hline Komedo & 10 & 25,0 & 21 & 63,6 & 31 & 100 & \\
\hline Papula & 28 & 70,0 & 11 & 33,3 & 39 & 100 & 0,002 \\
\hline Pustule & 2 & 5,0 & 1 & 3.1 & 3 & & \\
\hline Jumlah & 40 & 100 & 33 & 100 & 73 & 100 & \\
\hline
\end{tabular}

Berdasarkan tabel 3 dapat dilihat bahwa dari 31 siswi yang mengalami acne vulgaris dalam bentuk komedo, terdapat 21 siswi $(63,6 \%)$ yang mempunyai kepercayaan diri positif. Dari 39 siswi yang mengalami acne vulgaris dalam bentuk papula, terdapat 28 siswi (70\%) yang mempunyai kepercayaan diri negative. Sedangkan dari 3 siswi yang mengalami acne vulgaris dalam bentuk pustule terdapat 2 siswi $(5 \%)$ memiliki kepercayaan diri negatif. Berdasarkan uji statistik diperoleh nilai $\mathrm{p}$ value $=0,002(\mathrm{p}<0,05)$, dengan derajat kemaknaan $(\alpha=0,05)$. Ini berarti terdapat hubungan antara acne vulgaris dengan kepercayaan diri pada siswi di SMAN 2 Bangkinang Kota tahun 2017.

\section{PEMBAHASAN}

Berdasarkan hasil penelitian dapat dilihat bahwa dari 31 siswi yang mengalami acne vulgaris dalam bentuk komedo, terdapat 21 siswi $(63,6 \%)$ yang mempunyai kepercayaan diri positif. Dari 39 siswi yang mengalami acne vulgaris dalam bentuk papula, terdapat 28 siswi $(70 \%)$ yang mempunyai kepercayaan diri negative. Sedangkan dari 3 siswi yang mengalami acne vulgaris dalam bentuk pustule terdapat 2 siswi (5\%) memiliki kepercayaan diri negatif. Berdasarkan uji statistik diperoleh nilai $\mathrm{p}$ value $=0,002(\mathrm{p}<0,05)$, dengan derajat kemaknaan $(\alpha=0,05)$. Ini berarti terdapat hubungan antara acne vulgaris dengan kepercayaan diri pada siswi di SMAN 2 Bangkinang Kota tahun 2018.

Menurut asumsi peneliti remaja yang mengalami jerawat memiliki kepercayaan diri yang negative disebabkan karena mereka kurang merasa puas dengan keadaan dan penampilan fisiknya, sehingga remaja malu dengan tubuh yang dia miliki bahkan dia tidak mensyukuri keadaan dirinya serta akan sulit bergaul dengan keadaan di sekelilingnya.

Menurut hasil wawancara dengan siswi diperoleh hasil bahwa kepercayaan diri negative yang di miliki oleh siswi yang berjerawat dapat di lihat degan perilaku mereka yang merasa tidak puas, malu, kecewa dan menolak keadaan dirinya dengan adanya jerawat tersebut dan mereka juga mengatakan jerawat cukup merisaukan karena berhubungan dengan menurunnya kepercayaan diri akibat berkurangnya keindahan wajah penderita.

Menurut Fitriani (2014) pada umumnya remaja yang berjerawat akan mengalami perubahan keadaan psikologi berupa rendahnya kepercayaan diri. Mereka merasa malu dengan jerawat tersebut dan mempunyai mekanisme dan sumber koping yang kurang baik, sehingga jerawat dianggap suatu hal mempengaruhi kecantikan di wajah.

Menurut Suryani (2012) kondisi fisik dalam hal jerawat merupakan salah satu faktor yang 
mempengaruhi pembentukan dan perkembangan kepercayaan diri. Ada beberapa faktor yang dapat mempengaruhi kepercayaan diri, dapat berasal dari dalam dan dari luar individu itu sendiri. Faktor yang berasal dari dalam meliputi konsep diri, kondisi fisik, pengalaman, pendidikan dan faktor luar yaitu orang tua, teman sebaya dan sekolah.

Menurut Darmawanti (2013) kepercayaan diri merupakan suatu kemampuan untuk mempercayai kemampuan sendiri dan merasa positif tentang apa yang bisa dilakukan dan tidak mengkhawatirkan apa yang tidak bisa dilakukan. Rasa percaya diri penting di miliki oleh setiap orang karena rasa percaya diri mendorong seseorang untuk menghadapi situasi dengan pikiran jernih dan menerima kelemahan diri sehingga tidak terpuruk pada perasaan bersalah dan rendah diri yang dapat menghambat dalam mengoptimalkan potensi yang di miliki. Terkait dengan kepercayaan diri ini, menyatakan bahwa salah satu kelemahan generasi muda atau remaja adalah kurangnya kepercayaan diri

Perubahan biologis yang terdiri dari perubahan fisik merupakan pencetus yang berdampak pada tahap psikis. Perubahan kondisi fisik inilah yang berpengaruh pada kepercayaan diri. Penampilan fisik seperti wajah berjerawat yang tidak sesuai dengan gambaran ideal seorang remaja akan menimbulkan ketidak puasan sehingga menimbulkan rasa kurang percaya diri dan penampilan fisik merupakan penyebab utama rendahnya harga diri dan percaya diri seseorang. remaja yang memiliki kepercayaan diri yang rendah akan berorientasi pada penampilan fisik semata, karena mereka merasa tidak yakin akan kemampuan dan potensi dirinya pada hal-hal yang lain (Ridwan, 2013).

Hasil penelitian ini sesuai dengan penelitian yang dilakukan oleh Rikha (2014) dengan judul hubungan jerawat dengan tingkat kepercayaan diri pada X-XII SMA Negeri 7 Manado. Hasil penelitian menunjukkan bahwa kepercayaan diri memiliki hubungan positif dengan jerawat dimana keeratan korelasinya sangat lemah $(<0,20)$ sehingga dapat dikatakan terdapat hubungan signifikan antara kepercayaan diri dengan jerawat $(\mathrm{Sig}=0,013)$

\section{SIMPULAN}

1. Sebagian besar $(53,4 \%)$ responden menderita acne vulgaris dengan jenis papula

2. Sebagian besar $(54,8 \%)$ responden memiliki kepercayaan diri yang negatif

3. Terdapat hubungan acne vulgaris dengan kepercayaan diri pada siswi kelas XI di SMAN
2 Bangkinang kota tahun 2017 dengan p value 0,002 .

\section{SARAN}

1. Diharapkan penelitian ini dapat dijadikan sebagai bahan referensi untuk penelitian selanjutnya karena masih banyak lagi faktor lain yang menyebabkan kurangnya kepercayan diri pada penderita yang mengalami acne vulgaris dan bagi peneliti selanjutnya diharapkan peneliti yang lain agar melakukan penelitian yang lebih mendalam tentang acne vulgaris.

2. Diharapkan pada remaja putri yang menderita acne vulgaris agar dapat selalu percaya diri jika terjadi acne vulgaris. Dan diharapkan pada penelitian selanjutnya agar dapat melakukan penelitian lain yang berhubungan dengan akibat terjadinya acne pada remaja, seperti kurangnya konsep diri serta meneliti pada subjek yang lain yang berbeda.

\section{DAFTAR PUSTAKA}

Ahnan. (2014). Jerawat yang masih perlu anda ketahui. Yogyakarta: Graha Ilmu

Andrea. (2008). Cara dan Kebiasaan Membersihkan Wajah. Acne Vulgaris. Yogyakarta: Erlangg

Dipta. (2014). Hubungan faktor makanan dengan terbentuknya jerawat pada siswa dan siswi DI sman 1 Semarang. Diakses tanggal 09 Mei 2018

Darmawati. (2013). Kepercayaan Diri dan Pengambilan Keputusan pada Remaja. Jakarta: Nuha Medika

Efendi. (2013). Hubungan factor genetic dengan kejadian akne vulgaris . Journal Fakultas Kedokteran Universitas Diponegoro. Diakses tanggal 15 Mei 2018

Ellin,dkk(2015). Faktor-faktor yang mempengaruhi kejadian akne vulgaris pada siswa di SMAN 2 Kota Blitar. Diakses tanggal 01 Mei 2018

Hidayat, A.A. (2011). Riset Keperawatan dan Teknik Penulisan Ilmiah. Jakarta : Salemba Medika

Fitriani. (2012). Peranan Kulit dalam Mengatasi Terjadinya Akne Vulgaris. Jakarta. EGC,

Geldard. (2010). Kejadian dan Faktor Resiko Akne Vulgaris. Media Medika Indonesiana.

Hasan. (2015). Hubungan antara pemakaian jenis kosmetik dengan terjadinya akne vulgaris pada putrid di SMAN 1 Yogyakarta. Diakses tanggal 11 Mei 2018 
Hartini. (2012).Terapi Akne vulgaris. Jakarta: Nuha Medika

Kurniawaty. (2015). Hubungan antara kebersihan kulit wajah dengan kejadian acne vulgaris pada siswa SMAN 3 Klaten. Fkui. Diakses tanggal 11 Mei 2018

Lam. (2010). Hubungan perawatan wajah dengan terjadinya akne vulgaris pada Mahasiswa FK USU Stambuk. . Diakses tanggal $11 \mathrm{Mei}$ 2018

Notoadmodjo, Dr.Soekidjo, (2010). Metodologi Penelitian Kesehatan. Jakarta: Rineka Cipta

Ridwan. (2013). Hubungan gambaran diri dengan interaksi sosial pada remaja yang berjerawat. Fakultas Keperawatan Universitas Andalas

Rikha (2014) dengan judul hubungan jerawat dengan tingkat kepercayaan diri pada X-XII SMA Negeri 7 Manado

Sibero. (2015). Treatment For Acne Vulgaris. Diakses tanggal 01 Mei 2018

Suryani. (2012). Kejadian dan faktor resiko akne vulgaris. Media Medika Indonesiana.

Tahir. (2010). Acne Vulgaris: Simplified. Journal of Pakistan Association ofDermatologists. Diakses tanggal 11 Mei 2018

Wasitaatmadja. (2007). Ilmu Penyakit Kulit dan Kelamin, Edisi kelima,cetakan kedua, 3-8, Fakultas Kedokteran Universitas Indonesia, Jakarta.

Wulandari. (2010). Cara Jitu Mengatasi Jerawat. Jakarta: CV Andi Ofset

Wiliams. (2012). Dellavalle P. R., Garner, S., 2012. Acne Vulgaris Lancet;379: 361-72 